\title{
The neurological examination of non-complicated preterm newborns using the Saint-Anne Dargassies Scale from birth to term
}

\author{
Carla Ismirna Santos Alves', Áurea Nogueira de Melo²
}

\begin{abstract}
Objective: To describe the maturational development of 20 (aged 32-36 weeks) premature newborns (PNBs) without clinical or neurological complications from birth until term. Method: The Saint-Anne Dargassies Scale was applied every two weeks until the age of 37 weeks. Results: The PNBs showed normal Apgar and the growth in head circumference was adequate for postmentrual age. The Friedman ANOVA test found a significant difference only for the heel-to-ear angles from birth until term. The Saint-Anne Dargassies Scale detected changes in 11 PNBs and the most altered reflexes were: cardinal points, Moro, cross extension reflexe and automatic walking. These changes were found in the first 48 hours of life and in subsequent weeks until term. Conclusion: This finding alone justifies the neurological examination of PNBs, even if they show no clinical/neurological complications in the perinatal period and the importance of neuromotor assessment in preterm infants, as it enables detection and appropriate intervention.
\end{abstract}

Key words: preterm newborn, Saint-Anne Dargassies Scale, neonatal neurological examination.

O exame neurológico de recém-nascidos prematuros não complicados do nascimento ao termo pela escala de Saint-Anne Dargassies

\section{RESUMO}

Objetivo: Descrever a evolução maturacional de prematuros sem complicações clínicas ou neurológicas (RNP) do nascimento até atingir o termo. Método: A escala de SaintAnne Dargassies foi aplicada a cada duas semanas até atingir a idade de 37 semanas, considerado termo pela autora. Resultados: Os recém-nascidos prematuros apresentaram APGAR normal após a reanimação não invasiva e o crescimento do perímetro cefálico foi adequado à idade concepcional. O teste de Friedman ANOVA detectou diferenças significativas apenas para o ângulo calcanhar-orelha do nascimento ao termo. A escala de Saint-Anne Dargassies detectou 11 RNP com alterações nos reflexos: dos pontos cardinais, Moro, alargamento cruzado e o de marcha automática. Estas alterações foram encontradas nas primeiras 48 horas de vida e nas semanas subseqüentes até atingir 0 termo. Conclusão: Este achado por si justifica o exame neurológico de RNP mesmo que eles não apresentem complicações clínicas/neurológicas no período peri-natal, e mostra

\section{Correspondence}

Áurea Nogueira de Melo Rua Paulo Lira 2183 / 1301 59064-550 Natal RN - Brasil

E-mail: aureanmelo@yahoo.com.br

Received 28 January 2010

Received in final form 20 May 2010

Accepted 27 May 2010 que é importante a avaliação neuromotora nos prematuros, pois isso viabiliza a detecção e intervenção adequadas.

Palavras-chave: recém-nascidos prematuros, escala de Saint-Anne Dargassies, exame neurológico neonatal.

${ }^{1}$ Postgraduate Student from Program in Health Sciences (PPGCSA), Federal University of Rio Grande do Norte (UFRN), Natal RN, Brazil; ${ }^{2} \mathrm{MD}$, PhD, Federal University of Rio Grande do Norte (UFRN), Natal RN, Brazil. 
New medical technology has resulted in better survival rates for high-risk babies, thereby increasing the incidence of newborns with impaired neuropsychomotor development ${ }^{1,2}$. Because premature newborns (PNBs) are still developing, the detection and early intervention of possible maturation alterations may positively influence their prognoses. Since the 1990s, there has been a nearly $90 \%$ increase in survival rates of PNB weighing more than $750 \mathrm{~g}$. These babies are exposed to adverse conditions that may compromise their central nervous system and cause altered development. Although most have good prognoses, a considerable number present with sequelae, often incapacitating, with both family and social repercussions $^{3}$. PNBs at term do not exhibit the same development patterns as term newborns do. This impairment manifests itself in the newborns' incapacity to perform postural adjustments, owing to their low muscle tone and the immaturity of their organization systems ${ }^{4-6}$.

Another important item that distinguishes PNBs at term from term newborns is their primitives reflexes responses. These reflexes are present in both preterm and term newborns. Some neonatal reflexes disappear in the first 6 months of life, reappearing in the $2^{\text {nd }}$ semester as voluntary motor activity. Their disappearance is normal with the evolution of maturation, but this development pattern differs in the PNBs, because some reflexes may remain after a correction for gestational age, reflecting a delay in the disappearance of these primitive reflexes? ${ }^{7}$. Thus, documenting the assessment of prematurity reflex patterns at term may serve as a follow-up parameter in the first year of life of these PNBs.

For PNB assessment, the evaluation by Saint-Anne Dargassies Scale (SDS) ${ }^{8}$ stands out. This assessment includes neurological evaluation every two weeks until term, which she considers to be 37 weeks after conception.

We have observed in daily clinical practice that some PNBs without clinical and/or neurological complications have show favorable development. From this observation, the following question arose: would the neurological pattern of these premature newborns be normal or altered between birth and coming to full term?

Based on the Saint-Anne Dargassies Scale, our aim was to assess PNBs without clinical and/or neurological complications, define their first neurological examination and monitor neuromotor maturation from birth until term.

\section{METHOD}

\section{Patients}

The sample consisted of non-complicated PNBs, born and cared for at the neonatal intensive care unit (NICU) of the Januário Cicco Maternity School (MEJC), Natal/ Brazil, between August 2006 and August 2007. The sam- ple was of the non-probabilistic convenience type, selected according to the following inclusion criteria: [A] preterms cared for at the NICU of the MEJC; [B] gestational age (GA) between 30 and 36 weeks; [C] no clinical or neurological complications, based on neonatologist analysis. Exclusion criteria were as follows: [A] complicated preterms, that is, those with central nervous system (CNS) malformations; [B] neurological or clinical complications that lead to intubation or sedation; $[\mathrm{C}]$ complications from the mother's sedation in the first 48 hours of life; [D] pulmonary failure; [E] kidney failure; [F] apnea; [G] neonatal epileptic seizures and $[\mathrm{H}] \mathrm{CNS}$ infection.

\section{Procedures}

This is a prospective neonatal study, using the $\mathrm{SDS}^{8}$ to assess and describe the first neurological examination of the selected PNBs. The SDS assesses neurological patterns by [1] evaluating states of awareness classified as sleepiness, provoked wakefulness, spontaneous wakefulness, alternating wakefulness and sleep, and sedation; [2] assessing bed posture; [3] evaluating motor and neonatal reflexes through the assessment of cardinal point reflexes, finger squeezes, Moro reflexes, cross extensions reflexe and the automatic walking reflexes; [4] resistance to passive movements through of popliteal, foot-leg, and heel-to-ear angles; and [5] assessing active muscle tone through the evaluation of spontaneous movements, lower limbs straightenings, head straightenings, and the examination of neck flexor muscles (traction maneuver). During the application of the SDS, the head circumference $(\mathrm{HC})$ was measured. The PNBs were examined along the SDS every two weeks until the newborns reached the postmenstrual age of 37 weeks.

The study was conducted in two stages: stage I - collection of maternal records related to demographic data, risk factors for prematurity and Apgar score; stage II neurological examination using the SDS in the first 48 hours of life, and thereafter every two weeks until the newborn reached the postmenstrual age of 37 weeks, considered by this author to be term age. The SDS, requiring approximately 10 minutes to apply, was administered by two examiners (a pediatric neurologist and a physical therapist) to well-nourished PNBs. The assessment of awareness states followed the method proposed by Saint-Anne Dargassies ${ }^{8}$.

To evaluate articular angles $(\hat{A})$, a goniometer was adapted to obtain accurate measures, in addition to visual analysis (Fig 1).

Two values, ranging between 0 and 1 , were given for each item of the SDS, where 0 was considered the expected response and 1 the altered response. The final result obtained on the scale was classified as normal (unaltered) or altered (one or more altered items). 

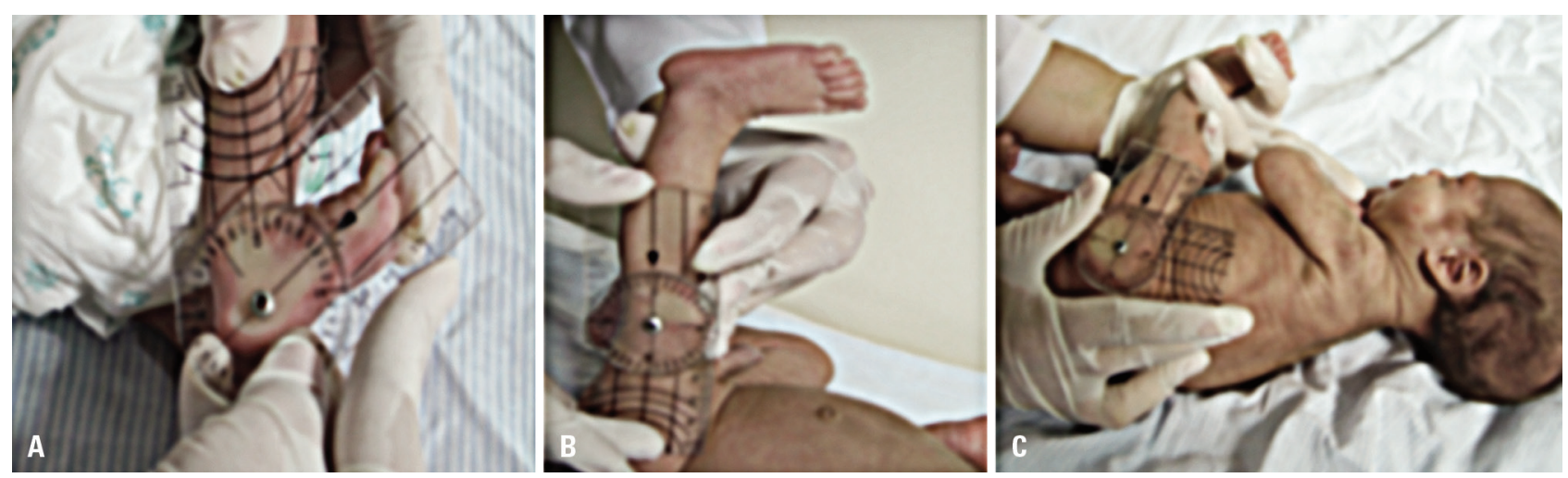

Fig 1. Goniometer adapted to assess the articular angles of 20 premature newborns. [A] foot-leg angle; [B] popliteal angle; [C] heel-to-ear angle.

Table. Clinical-demographic characteristics of 20 preterm newborns selected for a study of neurological pattern in the neonatal period until term.

\begin{tabular}{|c|c|c|}
\hline & & Percentage (\%) \\
\hline Number of patients & 20 & 100 \\
\hline Males / Females & $11 / 9$ & $55 / 45$ \\
\hline \multicolumn{3}{|l|}{ Gestational age } \\
\hline 32 weeks & 5 & 25 \\
\hline 33 weeks & 7 & 35 \\
\hline 34 weeks & 2 & 10 \\
\hline 35 weeks & 3 & 15 \\
\hline 36 weeks & 3 & 15 \\
\hline \multicolumn{3}{|l|}{ Ponderal gain } \\
\hline Adequate for gestational age & 17 & 85 \\
\hline Small for gestational age & 3 & 15 \\
\hline \multicolumn{3}{|l|}{ Delivery room resuscitation } \\
\hline $\mathrm{O}_{2}$ inhalation and tactile massage & 3 & 15 \\
\hline $\mathrm{O}_{2}$ inhalation & 10 & 50 \\
\hline $\mathrm{PPV}$ and $\mathrm{O}_{2}$ & 4 & 20 \\
\hline Not required resuscitated & 3 & 15 \\
\hline \multicolumn{3}{|l|}{ Prematurity etiology } \\
\hline Premature labor & 7 & 35 \\
\hline Infection & 6 & 30 \\
\hline $\mathrm{HBP}$ & 2 & 10 \\
\hline Premature rupture of membranes & 2 & 10 \\
\hline Other causes & 3 & 15 \\
\hline
\end{tabular}

PPV: progressive pulmonary ventilation; HBP: maternal high blood pressure.

The ultrasonography examination, although important in the follow-up of these preterms, was not performed, because it was not available at our facility and the transfer of these PNBs could have caused complications.

\section{Statistical analysis}

Statistic 6.0 software was used for descriptive and inferential analyses. The Friedman ANOVA test was used

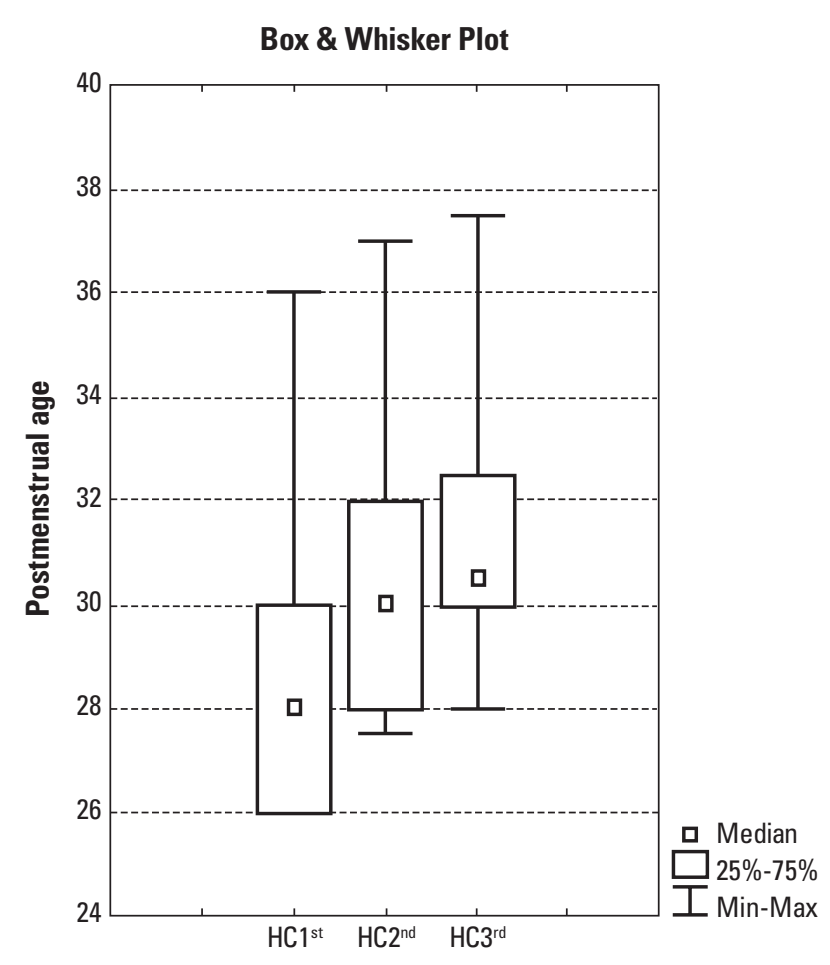

Fig 2. Head circumference (HC) development of 20 preterm newborns without clinical/neurological complications until term.

to assess articular angles. Correlation between the variables was determined using Kendall's test of concordance. A significance level of $5 \%$ was set for all the tests.

The study was approved by the postgraduate program's research committee, and only newborns whose parents signed an informed consent form were recruted.

\section{RESULTS}

Twenty non-complicated PNBs were selected, 11 (55\%) boys and 9 (45\%) girls. Table shows the main demographic characteristics of the PNBs. Maternal ages were grouped as follows: $15-20$ years (6/32\%); $20-25$ years (6/32\%); $25-30$ years ( $2 / 10 \%)$; $30-35$ years $(4 / 21 \%)$; and $>35$ years $(1 / 5 \%)$. Seventeen $(90 \%)$ were born from sin- 
gle pregnancies and $3(10 \%)$ were twin. Of the 19 gestating women, 11 (58\%) were multiparous and $8(42 \%)$ were primiparous. With respect to the number of prenatal care visits, 7 (37\%) had none, 4 (20\%) had either 1 or 2, 2 (11\%) had 3 , and $6(32 \%)$ had 4 or 5 . In regard to type of delivery, we found that 10 (50\%) had natural childbirth and 10 (50\%) cesarean section. Apgar score at the $1^{\text {st }}$ minute was 3-9 and $5^{\text {th }}$ minutes $8-9$ showed satisfactory development after non-invasive resuscitation.

The Friedman test showed a significant difference $(\mathrm{p}<0.00009)$ between $\mathrm{HC}$ measurements from prematurity period and at term (Fig 2). The $\mathrm{HC}$ measurement at the final assessment on the SDS obtained a higher mean and had the lowest coefficient of variation using Pearson's method (9.31\%), compared to the coefficients of variations of $\mathrm{HC}$ measures in the $1^{\text {st }}(10.05 \%)$ and $2^{\text {nd }}(10.48 \%)$ assessment.

The SDS allowed us to detect 11 PNBs with alterations in their first neurological examination. In the last assessment of articular angles, we observed that 19 (95\%) PNBs had normal popliteal angle measures and only 1 (5\%) showed an increase. The examination of articular angles (popliteal, foot-leg and heel-to-ear) used in the SDS with PNBs submitted to the Friedman test and Kendall's coefficient demonstrated significant differences only between the 3 measures of heel-to-ear angle with $p<0.018$, $r=0.27$, means of $2.333,2.083,1.583$ and medians of 0.916 , 0.666 and 0.333 respectively.

The altered neonatal reflexes found during the three assessments of SDS prematurity were: the $1^{\text {st }}$ examination found 5 suspects aged between 32 and 33 weeks GA ( 4 alterations in cardinal point reflexes and 1 alteration in the Moro reflex); in the $2^{\text {nd }}$ assessment, 9 suspects aged between 33 and 36 weeks GA were detected, with 4 alterations in the cross extension reflex and 5 in automatic walking reflex; in the $3^{\text {rd }}$ examination there were 2 suspects with altered cross extension reflex and automatic walking reflex, with ages ranging from 33 to 35 weeks GA.

\section{DISCUSSION}

The neonatal period has drawn the attention of researchers because it provides relevant information for understanding possible developmental alterations in these children $^{9-10}$. In the neonatal period, the assessment of the Apgar score is an important point. It is known that an Apgar below 4 in the 5-minute, associated with low weight, is a complicating factor that may put the neuropsychomotor development of a newborn at risk ${ }^{11-13}$. The results of this study show that all the preterms evaluated were well after non-invasive resuscitation, obtaining Apgar scores above 7 in the 5 -min. This observation may explain the excellent development those preterms until term age.

The $\mathrm{HC}$ evaluation in the prematurity period prior to term showed that there is indeed greater cephalic growth in the two first weeks of life and that this measure is directly related to the absence of clinical and neurological complications. This finding of $\mathrm{HC}$ growth in preterms corroborates the studies conducted by Saint-Anne Dargassies $^{8}$, since she established that $\mathrm{HC}$ growth must accompany the growth and maturation of the CNS after birth.

With respect to posture, we found that all the PNBs were considered normal at term in all the evaluations. This finding reflects adequate neurological maturation for their corrected ages, corroborating the results of Bonvicine et al. ${ }^{14}$.

Statistical analysis of articular angles shows us that the heel-to-ear angle is more sensitive in detecting tonus alterations than the popliteal angle used by Kato ${ }^{15}$. This difference may be related to the measuring method, because the current work, in addition to visual analysis, used a goniometer to measure the angle. This assessment technique was considered by Kato ${ }^{16}$ as more reliable.

However, $\mathrm{Kato}^{16}$ did not evaluate the other articular angles of the lower limbs, a fact that did not allow him to compare the angles. In this study, we assessed popliteal, heel-to-ear and foot-leg angles, comparing the results statistically. Thus, it can be observed that, despite being altered, the popliteal angle showed no statistically significant differences, in contrast with the heel-to-ear angle did. This finding is agreement with others that found differences for the heel-to-ear angle ${ }^{17}$.

Would the assessment of the heel-to-ear angle have a stronger predictive power for the detection of future muscle tone alteration in PNBs? Other follow-up studies could confirm this finding as well as its predictive value.

The investigation of neonatal reflexes is important in the examination of PNBs primarily because it reflects the CNS integrity, not only during its intrauterine development but also during the maturation process until they reach term age.

As discussed above, the first premature newborn examination at term showed important alterations, mainly in tonus and primitive reflexes. With respect to reflexes, it was observed that in the first assessments, there was a larger number of preterms with alterations comparison with last SDS examination, where only there were 2 suspects based upon cross extension reflex and automatic walking reflex.

The present study was carried out in a regional maternity. The weakness of study is related to this specific setting. So the weakness was the limited access to ultrasound scan.

The SDS allowed us to detect 11 PNBs with alterations in their first neurological examination. These alterations were found in the first 48 hours of life and in subsequent weeks until they reached term. These findings alone justify 
the neurological examination in PNBs. Salt and Redshaw ${ }^{18}$ argue that a 2-year follow-up of these PNBs is important, given that they may have altered intellectual functions and consequently compromised school performance.

In conclusion, the findings of the present study indicate the importance of a neurological assessment in premature newborns, even if they have no clinical/neurological complications, given that it enables the identification of PNBs who are at risk and permits adequate intervention.

\section{REFERENCES}

1. Rugolo LMSS. Growth and developmental outcomes of the extremely preterm infant. J Pediatr (Rio J). 2005;81 (Suppl 1):S101-S110.

2. Fawke J. Neurological outcomes following preterm birth. Semin Fetal Neonatal Med 2007;12:374-382

3. Mello RR, Dutra MVP, Silva KS, Lopes JMA. The predictive value of neonatal neurological assessment and neonatal cranial ultrasonography with respect to the development of very low birth weight premature infants. Rev Saude Publica 1998;32:420-429.

4. Mello RR, Meio MDBB, Morsch DS, et al. Normal neonatal cerebral ultrasonography in preterm infants - Is it possible to calm down the parents? J Pediatr (Rio J) 1999;75:45-49.

5. Mercuri E, Guzzetta A, Laroche S, et al. Neurologic examination of preterm infants at term age: comparison with term infants. J Pediatr 2003;142: 647-655.

6. Amess P, Mcferran C, Khan Y, Rabe H. Early prediction of neurological ouctcome by term neurological examination and cranial ultrasound in very preterm infants. Acta Paediatr 2009;98:448-453.
7. Olhweiler L, Silva AR, Rotta NT. Primitive reflex in premature healthy newborns during the first year. Arq Neuropsiquiatr 2005;63:294-297.

8. Saint-Anne Dargassies. Desarrollo neurologico del recien nacido de termino y prematuro. Panamericana, Buenos Aires 1997.

9. Luchetta M, Formiga CKMR, Tudella E. Antecedentes obstétricos/neonatais e desenvolvimento motor-adaptativo de crianças pré-termo e com baixo peso entre 24 e 36 meses de idade. FisioBrasil 2007:8:255-260.

10. Ohgi S, Arisawa K, Takahashi T, et al. Neonatal behavioral assessment scale as a predictor of later developmental disabilities of low birth-weight and/ or premature infants. Brain Dev 2003;25:313-321.

11. Manacero $S$, Nunes ML. Evaluation of motor performance of preterm newborns during the first months of life using the Alberta Infant Motor scale (AIMS). J Pediatr 2008;84:53-59.

12. Wolfe MJ, Beunen G, Casaer P, Wolf B. Neonatal neurological examination as a predictor of neuromotor outcome at 4 months in term low-Apgar-score babies in Zimbabwe. Early Hum Dev 1998;51:179-186.

13. Thorngren-Jerneck K, Herbst. Low 5-minute Apgar score: a population-based register study of 1 million term births. Obstet Gynecol 2001;98:65-70.

14. Bonvicine C, Quibaó EC, Silva PN, Asa SKP, Gaetan ESM. Head control acquisition in preterm and full-term infants. Fisio Pesq 2005;12:45-50.

15. Kato T, Okumura A, Hayakawa F, Itomi K, Kuno K, Watanabe K. Popliteal angle in preterm infants wih periventricular leukomalacia. Pediatr Neurol 2005;32:84-86.

16. Kato T, Okumura A, Hayakawa F, Tomi K, Uno K, Watanabe K. Popliteal angle of low birth weight infants during the first year of life. Pediatr Neurol 2004;30:244-246

17. Silva ES, Nunes ML. The influence of gestacional age and birth weight in the clinical assessment of the muscle tone of healthy term and preterm newborns. Arq Neuropsiquiatr 2005;63:956-962.

18. Salt A, Redshaw M. Neurodevelopmental follow-up after preterm birth: follow- up after two years. Early Hum Dev 2006;82:185-197. 